\title{
Aplikasi Rekapitulasi Suara Yang Diperoleh Calon Legislatif Pada Pemilihan Umum
}

\author{
Ulfah Indriani ${ }^{1}$, Nita Syahputri ${ }^{2}$ \\ Universitas Potensi Utama \\ Jl. KL. Yos Sudarso KM.6,5 Tanjung Mulia, Medan \\ batakeraton@gmail.com¹, nieta20d@gmail.com²
}

\begin{abstract}
General Election is a democratic party held every 5 (five) years. General elections are held to elect state officials from the President, Regional Head and Legislative Members. There are so many people who really want that position because of the huge income, luxurious facilities and high social level. Many people are willing to spend large amounts of money in order to be able to occupy these seats. This is because each candidate must get a large number of people's votes so that the candidates cannot work alone in order to gain votes. And if the election has arrived and the people have chosen, then the legislative candidates will try as soon as possible to find out whether they will be elected or not. The basis for the vote calculation is form $C 1$ which is the result of manual recapitulation at the polling station (polling station). This form is very much even reaching thousands of files. The problem is that it is difficult and takes a long time if we have to count thousands of sheets and want to see the number of votes and voice mapping in the Electoral District (Electoral District) manually. Therefore, the researcher tried to make an application that could facilitate candidates for legislative candidates in carrying out vote counting. With this application it will be easy and fast in knowing the number of votes obtained. With this application, Legislative candidates will find out whether they can be elected or not. And the conclusion of this discussion is how a technology in the world of computers will greatly help candidates for the legislature to cut time and get detailed information about the votes obtained.
\end{abstract}

Keywords: General Elections, Recapitulation, Votes, Applications

Abstrak- Pemilihan Umum merupakan sebuah pesta demokrasi yang diadakan setiap 5 (lima) tahun sekali. Pemilihan umum dilakukan untuk memilih para pejabat negara mulai dari Presiden, Kepala Daerah dan Anggota Legislatif. Banyak sekali orang yang sangat menginginkan posisi tersebut dikarenakan oleh pendapatan yang besar, fasilitas mewah dan tingkat sosial yang tinggi. Banyak orang yang rela menghabiskan uang dalam jumlah besar agar dapat menduduki kursi tersebut. Hal ini dikarenakan setiap calon harus mendapatkan suara rakyat dalam jumlah besar sehingga menyebabkan para calon tidak bisa bekerja sendiri agar dapat meraup suara. Dan jika pemilihan sudah tiba dan rakyat sudah memilih, maka para calon anggota Legislatif pun akan secepat mungkin berusaha untuk mengetahui pakah ia akan terpilih atau tidak. Dasar yang menjadi perhitungan suara adalah formulir C1 yang merupakan hasil rekapitulasi manual di TPS (Tempat Pemungutan Suara). Formulir ini sangat banyak bahkan mencapai ribuan berkas. Yang menjadi masalah adalah sulit dan memakan waktu yang lama jika kita harus menghitung ribuan lembar tersebut dan ingin melihat jumlah suara dan pemetaan suara yang ada pada Dapil (Daerah Pemilihan) secara manual. Oleh karena itu Peneliti mencoba membuat suatu aplikasi yang dapat memudahkan calon Legislatif dalam melakukan perhitungan suara. Dengan Aplikasi ini maka akan mudah dan cepat dalam mengetahui jumlah suara yang diperoleh. Dengan aplikasi ini maka calon Legislatif akan mengetahui ia dapat terpilih atau tidak. Dan kesimpulan dari pembahasan ini adalah bagaimana suatu teknologi dalam dunia komputer akan sangat membantu para 
calon Legislatif untuk memangkas waktu dan mendapatkan informasi secara detail mengenai perolehan suara yang didapat.

Kata kunci: Pemilihan Umum, Rekapitulasi, Suara, Aplikasi

\section{PENDAHULUAN}

\subsection{Latar Belakang}

Pemilihan Umum merupakan sebuah peristiwa yang besar dalam suatu negara yang menganut paham demokrasi. Khususnya di Indonesia, pemilihan umum merupakan momen yang menentukan kelanjutan suatu Negara dan dilaksanakan 5 (lima) tahun sekali. Seiring berjalannya waktu demokrasi terus berkembang. Pada tahun 1998 adalah momen bersejarah dimana ditahun tersebut merupakan peristiwa jatuhnya rezim yang disebut otoriter dan disebut juga era reformasi. Pemilihan Umum pun tak lagi hanya sekedar memilih siapa yang akan menjadi Presiden, namun juga memilih siapa yang akan menduduki kursi di parlemen menjadi anggota Dewan Perwakilan Rakyat (DPR) baik itu di pusat, provinsi atau kabupaten kota. Hal ini membuat munculnya banyak Partai Politik, dan masing - masing dari Partai Politik mencalonkan para kadernya untuk menduduki kursi anggota dewan. Para kadernya juga yang kian hari makin gencar untuk meningkatkan popularitas dan meraup simpati dari relawan sebanyak mungkin agar dapat menduduki kursi tersebut. Bagaimana tidak, kursi anggota dewan tersebut merupakan posisi yang sangat menggiurkan. Selain memang menerima gaji yang besar, fasilitas mewah, status sosial yang tinggi juga dapat memiliki pengaruh yang sangat besar dikarenakan anggota dewan merupakan orang - orang yang membuat/merumuskan UU (Undang - undang) dalam suatu negara. Dengan kesemua itu membuat orang beramai - ramai ingin menjadi anggota dewan.

Tidak gampang untuk menjadi anggota legislatif, mengingat jumlah penduduk Indonesia yang cukup besar maka suara yang harus didapat juga harus besar. Pada saat pemilihan dimulai maka para anggota legislatif akan mulai menghitung berapa perolehan suara yang mereka dapat. Pada dasarnya perhitungan suara sudah dilakukan oleh KPU (Komisi Pemilihan Umum) dan juga ada lembaga - lembaga survey lain yang melakukan perhitungan cepat atau QuickCount, namun para calon anggota legislatif tersebut sudah pasti tidak sabar untuk menunggu hasil perhitungan suara dari KPU yang memakan waktu lama serta dari QuickCount yang sejatinya bukan perhitungan pasti. Para anggota legislatif akan mengerahkan semua sumber daya yang ia punya untuk mendapatkan form C1 yang menjadi dasar perhitungan suara. Seluruh form $\mathrm{C} 1$ akan rekap dan dihitung untuk melihat berapa suara yang ia miliki dan lawan politiknya. Form C1 berisi semua hasil suara dari proses pemilihan, jika dalam suatu pemilihan ada 15 sampai 20 partai dan dalam partai tersebut ada 10 sampai 12 orang calon maka akan sangat sulit sekali untuk medatanya jika dilakukan secara manual. Maka dari itu peneliti membuat sebuah aplikasi yang dapat membantu para calon legislatif untuk menghitung perolehan suara yang ada. Dengan aplikasi maka para calon legislatif akan dengan mudah untuk mengetahui data dalam form C1. Para calon akan dengan mudah mengetahui berapa suara yang ia peroleh dan lawan politiknya serta melihat grafik 
perbandingan suara dari semua kandidat yang bertanding dalam pemilihan. Berdasarkan hal tersebut, penulis bermaksud untuk mengadakan penelitian dengan judul adalah "Aplikasi Rekapitulasi Suara Yang Diperoleh Calon Legislatif Pada Pemilihan Umum".

\section{METODOLOGI PENELITIAN}

\subsection{Tempat dan Waktu Penelitian}

Penelitian ini dilakukan di wilayah Kabupaten Deli Serdang yang merupakan salah satu Dapil (Daerah Pemilihan) di Sumatera Utara. Lama waktu penelitian yang dilakukan adalah 2 bulan.

\subsection{Alur Analisis}

Metodologi rekayasa perangkat lunak yang digunakan adalah berorientasi objek, sehingga perancangan pada penelitian ini akan menggunakan notasi Unified Modelling Language (UML). Adapun tahapan-tahapan yang akan dilaksanakan adalah sebagai berikut:

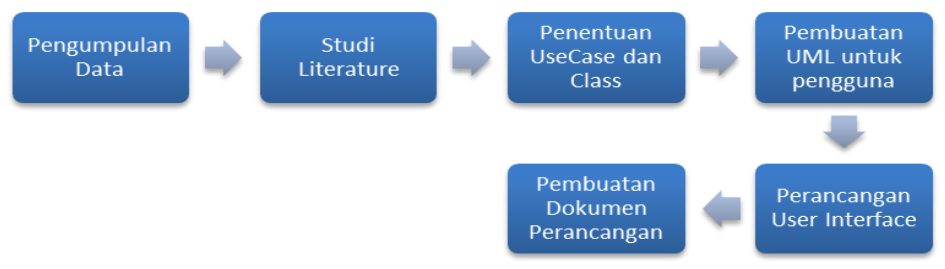

Gambar 1. Alur Analisis

\subsection{Pengumpulan Data}

Data yang digunakan berasal dari dokumen rekayasa kebutuhan hasil penelitian sebelumnya. Namun jika dirasa perlu, dilakukan pengumpulan data kembali dari calon pengguna sistem sebagai pelengkap dokumen yang kurang atau untuk verifikasi data dokumen.

\subsection{Studi Literatur}

Tahap ini dilakukan pengumpulan materi yang berasal dari tulisan-tulisan karya ilmiah, artikel populer, serta tanggapan dari praktisi dan profesional mengenai perancangan sistem yang baik.

\section{HASIL DAN PEMBAHASAN}

Hasil dan Pembahasan dari Aplikasi Rekapitulasi Suara Yang Diperoleh Calon Legislatif Pada Pemilihan Umum adalah sebagai berikut :

\subsection{Tampilan Hasil}

Berikut tampilan hasil dari aplikasi Aplikasi Rekapitulasi Suara Yang Diperoleh Calon Legislatif Pada Pemilihan Umum. 
Prosiding Seminar Nasional Riset Information

ISSN: 2686-0260

Science (SENARIS)

September 2019

Hal:88-95

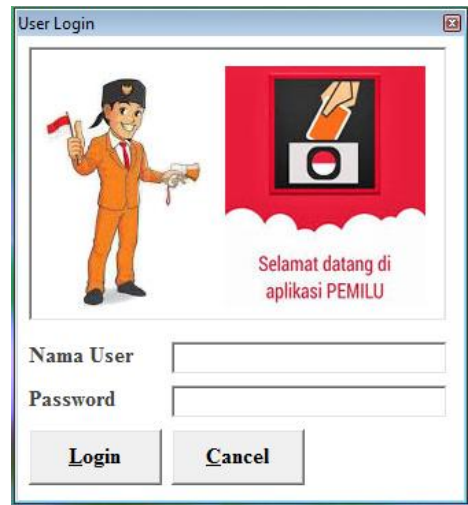

Gambar 2. Menu Login Aplikasi

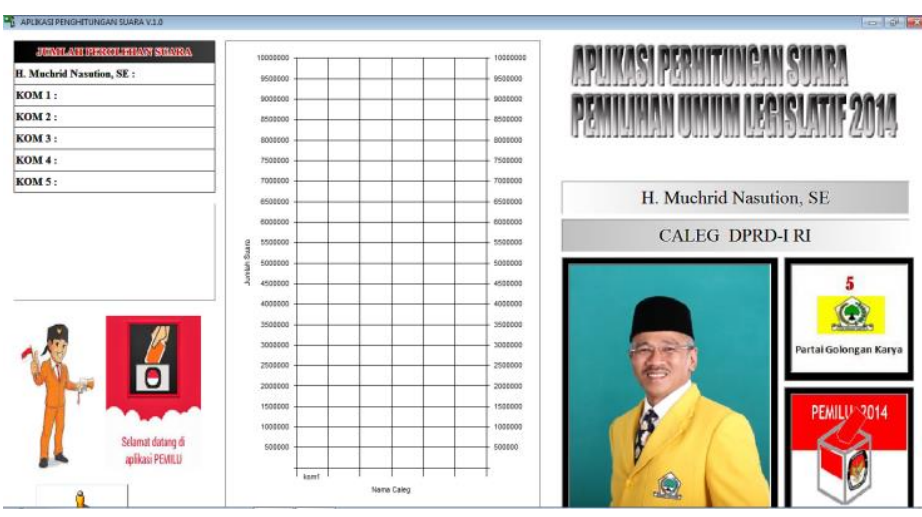

Gambar 3. Halaman Utama

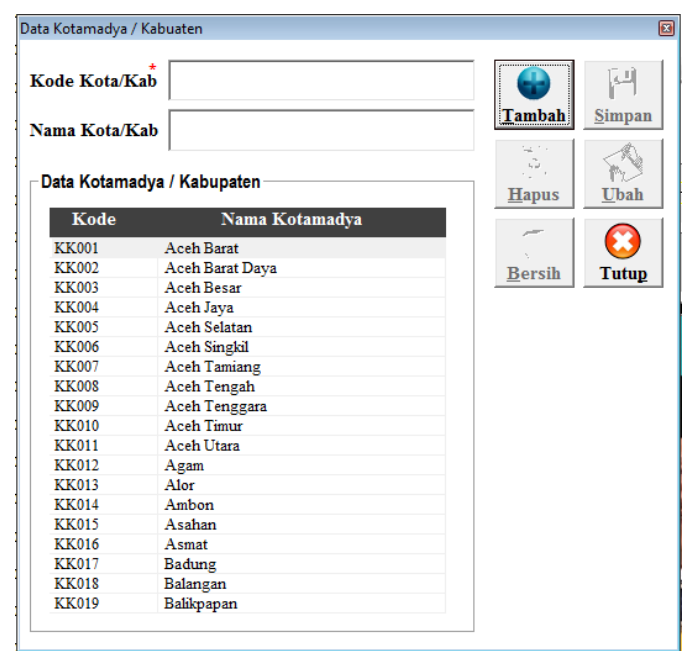

Gambar 4. Input Data Kabupaten/Kota 


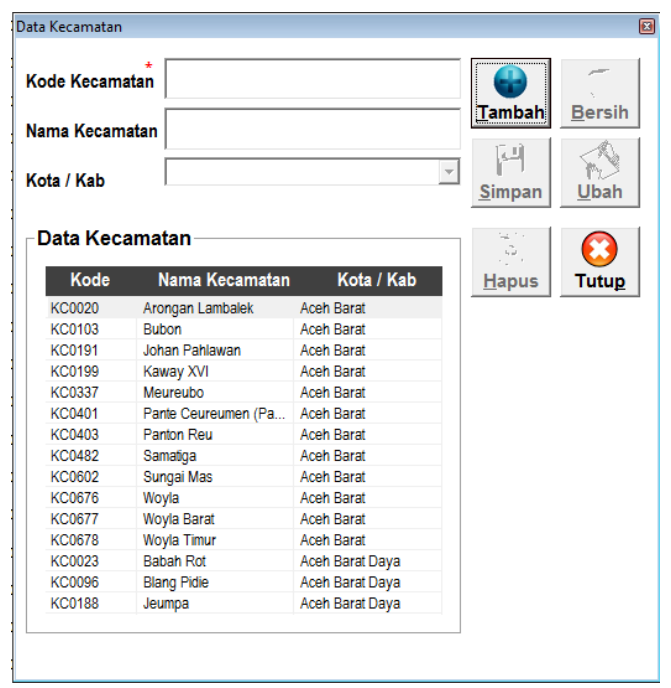

Gambar 5. Input Data Kecamatan

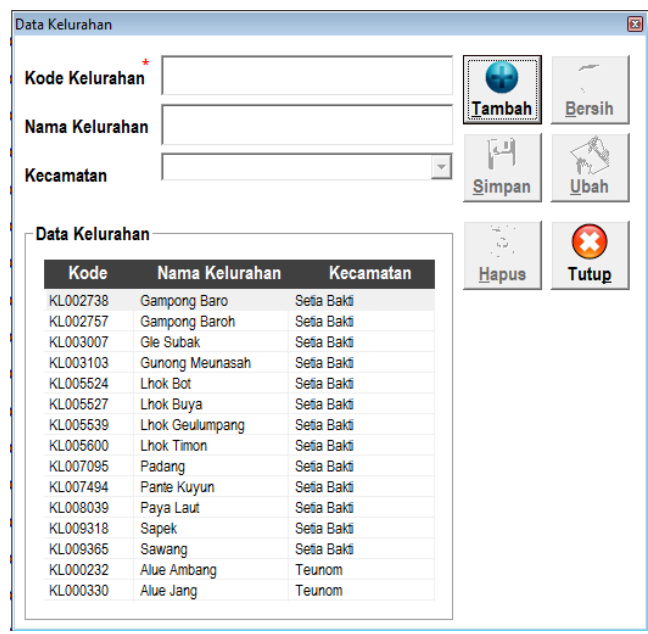

Gambar 6. Input Data Kelurahan

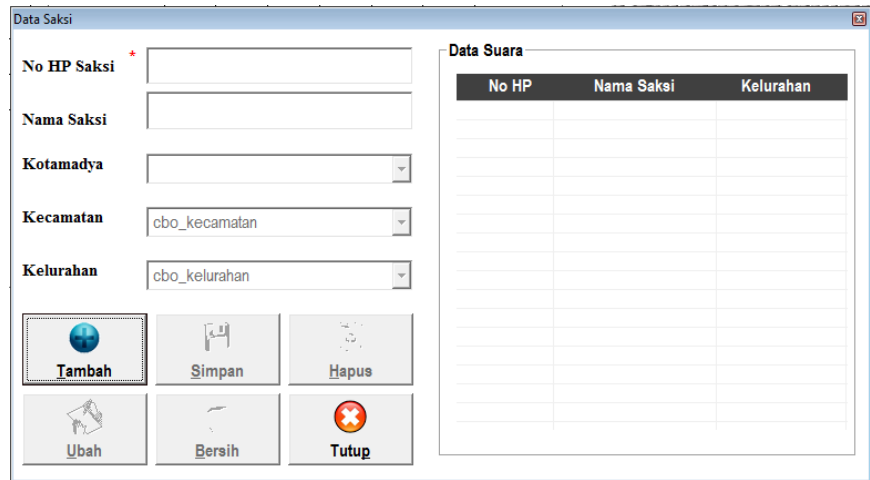

Gambar 7. Input Data Saksi 


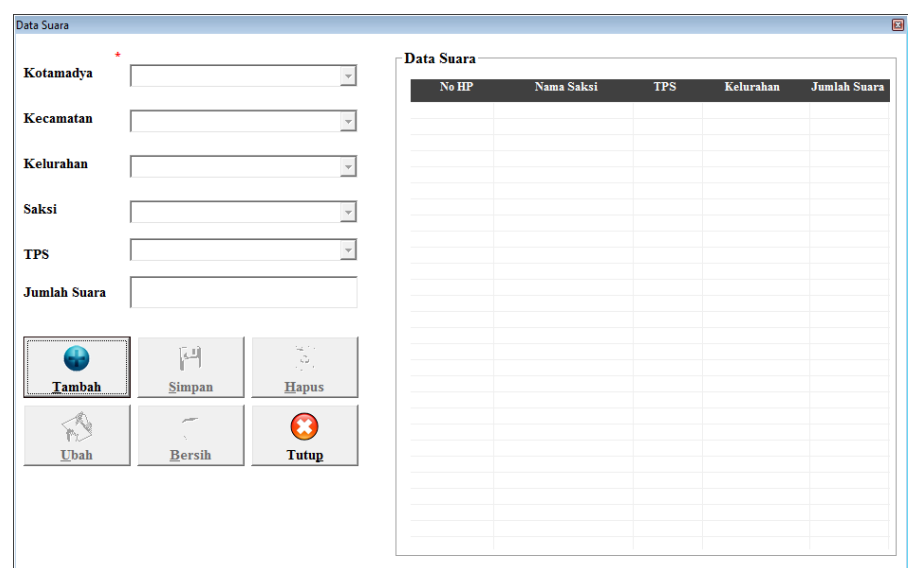

Gambar 8. Input Data Suara di TPS

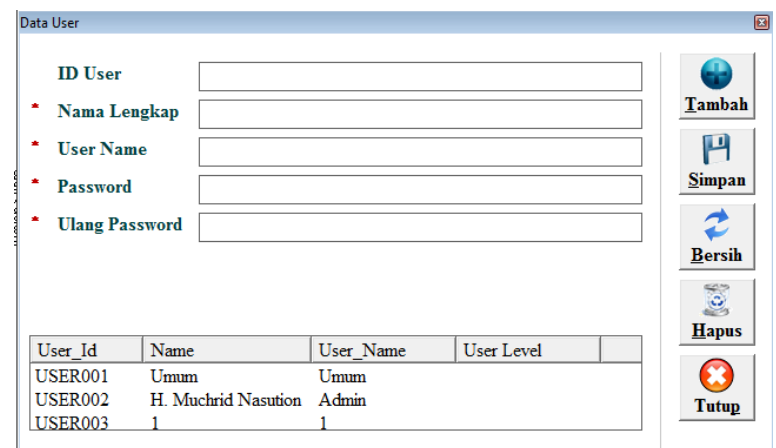

Gambar 9. Input Data Pengguna

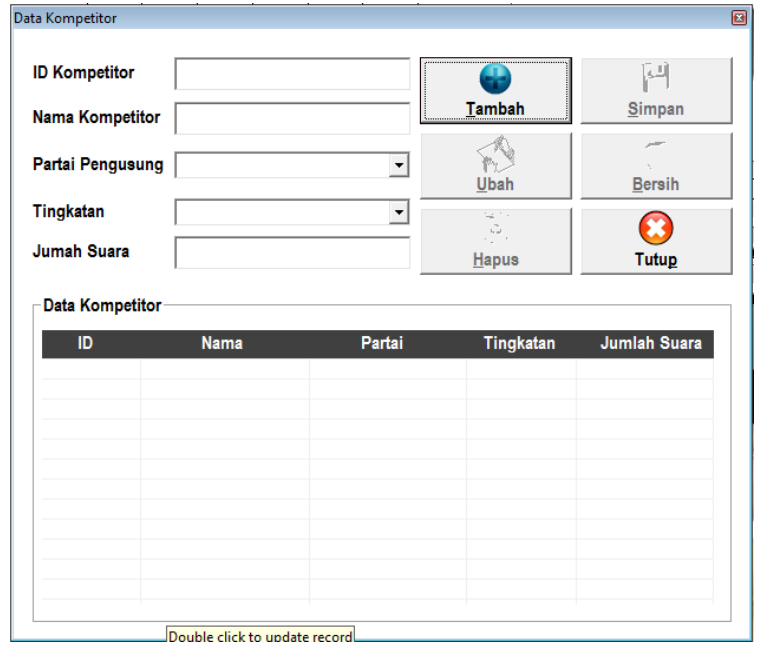

Gambar 10. Input Data Kompetitor 


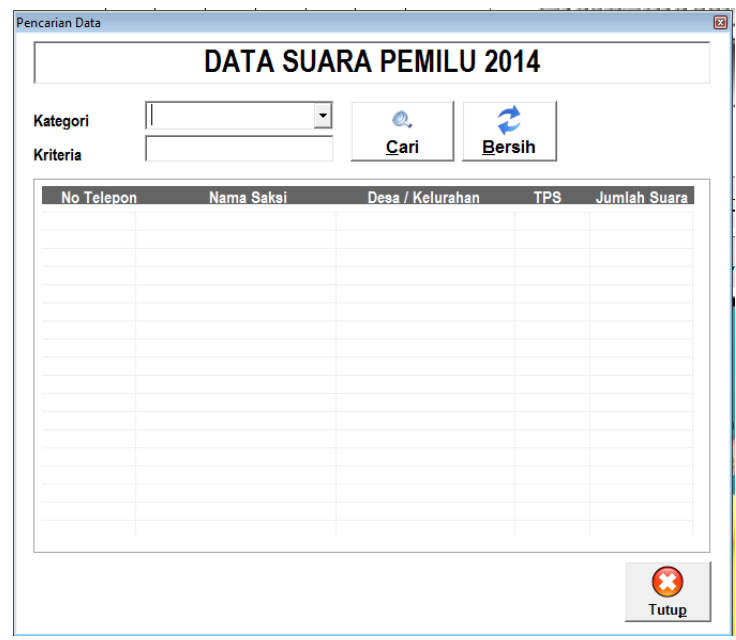

Gambar 11. Menu Pencarian Data

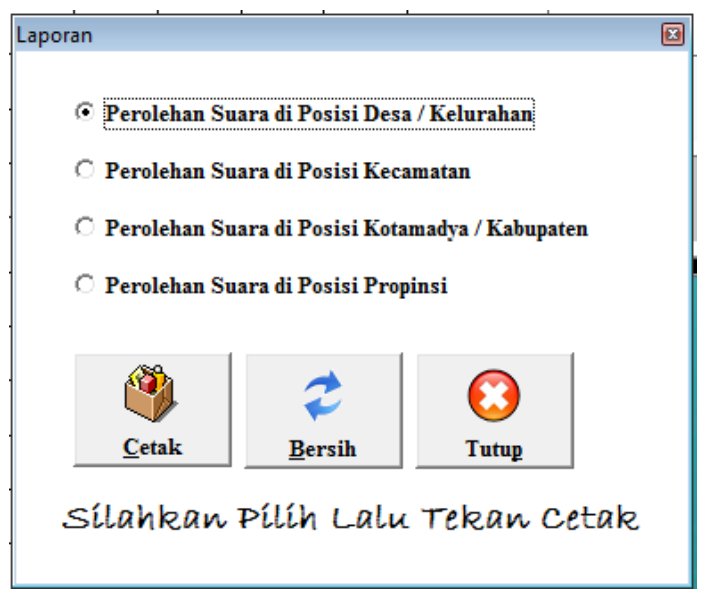

Gambar 12. Menu Laporan

\subsection{Pembahasan}

Dalam perancangan Aplikasi Rekapitulasi Suara Yang Diperoleh Calon Legislatif Pada Pemilihan Umum ini, penulis menggunakan aplikasi bahasa pemrograman Visual Basic sebagai program dalam mendesain suatu aplikasi dan menggunakan Microsoft Access sebagai databasenya. Perintah-perintah yang ada pada program yang penulis buat juga cukup mudah untuk dipahami karena pengguna hanya perlu mengklik tombol-tombol yang sudah tersedia sesuai kebutuhan. Alasan di atas dapat menjadi tujuan untuk meningkatkan efektivitas kerja dan bisa lebih memaksimalkan sumber daya yang terkait dengan proses perhitungan suara pada pemilihan Umum yang berlangsung.

\section{KESIMPULAN}

Dari penjabaran diatas dapat disimpulkan bahwa aplikasi rekapitulasi suara ini merupakan suatu alat bantu bagi para calon Legislatif dalam menghitung suara yang ia dan juga lawan politiknya peroleh. Dengan adanya aplikasi ini akan sangat mudah mendapatkan semua informasi yang ada dalam perhitungan suara. Baik suara secara keseluruhan, perkecamatan, perdesa, grafik perbandingan perolehan 
suara dengan competitor dan data yang diperlukan lainnya. Dengan adanya aplikasi ini secara tidak langsung sudah dapat mewakili hasil perhitungan suara di KPU dikarenakan inpu data aplikasi berasal dari data yang valid yaitu formulir C1 yang sejatinya merupakan data valid dan sah dari hasil perhitungan suara di TPS. Laporan dari aplikasi ini juga bisa jadi bahan acuan jika nantinya terjadi kecurangan atau kesalahan dalam entry data KPU, sehingga para calon tidak lagi merasa was - was atau ragu dalam mengetahui terpilih atau tidaknya ia sebagai anggota Dewan Perwakilan Rakyat.

\section{DAFTAR PUSTAKA}

[1] Adi, Isbandi Rukminto. (2005), Ilmu Kesejahteraan Sosial \& Pekerjaan Sosial, Depok: FISIPUI

[2] Budiarjo, Miriam.1993. Dasar-Dasar Ilmu Politik. Jakarta:PT. Gramedia Pustaka Utama.

[3] Musa, Moh. dan Titi Nurfitri. 1988. Metodelogi Penelitian. Fajar Agung. Jakarta

[4] Singarimbun, Masri, dan Sofian Effendi. (1995). Metode Penelitian Survai. Jakarta: PT. Pusaka LP3ES Indonesia

[5] Wilson, J. P., and Rascati, K. L., 2001, Pharmacoeconomic, Malone, Patrick M., Kier, Karen, L., and Stanovich, John, E., in Drug Information, 2nd Edition, 209-231, McGraw-Hill, New York

[6] Wyatt Keith and Carl Schroeder.(1998).Harmony and Theory. Minnesota : Hal.Leonard Corporation International.

[7] Wilson, John. 2000. Volunteering. Annual Review of Sociology 